\title{
Avaliação de sustentabilidade e habitabilidade de blocos de solo-cimento segundo a norma ABNT NBR 15575
}

\author{
Evaluation of soil-cement blocks for sustainability \\ and habitability in accordance to the Brazilian \\ standard ABNT NBR 15575
}

Priscila Giorgi ${ }^{1}$, Giane de Campos Grigoletti ${ }^{2}$, Rogério Cattelan Antocheves de Lima ${ }^{2}$, Luciani Somensi Lorenzi ${ }^{3}$

\author{
${ }^{1}$ Universidade Regional Integrada do Alto Uruguai-URI, Santo Ângelo, RS, Brasil. \\ e-mail: prigiorgi@hotmail.com \\ ${ }^{2}$ Laboratório de Materiais de Construção Civil - LMCC - Centro de Tecnologia - Universidade Federal de Santa Maria, \\ Av. Roraima, n. 1.000, Santa Maria, RS, Brasil. \\ e-mail: giane.c.grigoletti@ufsm.br, rogerio@ufsm.br \\ ${ }^{3}$ Laboratório de Ensaios e Modelos Estruturais - LEME - Escola de Engenharia - Universidade Federal do Rio Grande \\ do Sul, Porto Alegre, RS, Brasil. \\ e-mail:luciani.lorenzi@ufrgs.br
}

\section{RESUMO}

A indústria da construção civil é responsável pela extração de grande parte dos recursos naturais. Esse fato gera a preocupação em construir edificações com menor impacto negativo possível, que, entre outras vantagens, usem materiais com potencial de reincorporação na natureza e tenham baixo conteúdo energético. A terra pode ser uma alternativa para atingir esses objetivos.

O solo-cimento é um material curado sem queima, composto de terra prensada e estabilizada com cimento, já normatizado pela Associação Brasileira de Normas Técnicas (ABNT), com vantagens que vão desde a fabricação até sua utilização no canteiro de obras. Para melhor aceitação é necessário que se conheça suas propriedades e seu desempenho.

Este artigo apresenta a avaliação de desempenho de um sistema de vedação vertical externo, composto por blocos vazados de solo-cimento sem função estrutural para habitações térreas, seguindo as determinações da norma técnica ABNT NBR 15.575 - Edificações habitacionais: desempenho, com foco em habitabilidade e sustentabilidade. Analisou-se, como exigência de habitabilidade, o fator estanqueidade à água da chuva e permeabilidade à água, e como exigência de sustentabilidade, o fator durabilidade, com a realização do ensaio de ação de calor e choque térmico.

Os resultados indicam que o sistema de vedação vertical externo atendeu aos limites estabelecidos na norma para os ensaios de estanqueidade à água da chuva, ação de calor e choque térmico, o que não ocorreu no ensaio de permeabilidade à água. Através dos resultados dos ensaios, verificou-se que o sistema de vedação vertical composto por blocos vazados de solo-cimento possui potencial para aplicação na construção, mas ainda há a necessidade de mais estudos sobre o sistema.

Palavras-chave: Solo-cimento. Desempenho de Edificações. Habitabilidade. Sustentabilidade

\section{ABSTRACT}

The building sector is responsible for significant consumption of natural resources. Sustainable buildings contributes to the reduction of environmental impacts such as energy consumption, soil, and water and air pollution. In this scenario, raw soil as a building material has become an alternative for the development of sustainable buildings.

Raw soil is cured without burning. Raw soil mixed with Portland cement, pressed and stabilized produces 
soil-cement blocks and they are already regulated by the Brazilian technical standards association (Associação Brasileira de NormasTécnicas - ABNT) and possesses many advantages related to its manufacturing and use. To increase its acceptance and verify its efficiency as a building material for social housing, it is necessary to investigate its properties and performance.

The present study aimed to evaluate the performance of an external vertical sealing system composed of hollow blocks of soil-cement without structural function for social housing, following determinations of ABNT NBR 15575, focusing on the requirements of habitability and sustainability. It was analysed tightness against rainwater and water permeability, habitability requirements, and durability, sustainability requirement, through heat action and thermal shock testings.

The system met limits set by standards for tightness against rainwater and heat action and thermal shock, but not for water permeability. The vertical sealing system composed of hollow blocks of soil-cement has potential for application in the construction, but there is still need for more studies on the system.

Keywords: Soil-cement. Building Performance. Habitability. Sustainability.

\section{INTRODUÇÃO}

O setor da construção civil consome mais da metade dos recursos naturais extraídos do planeta, além de grande quantidade de energia na sua produção e seu transporte [1]. Segundo MELO et al.[2], a produção do cimento Portland exige que sejam atingidas temperaturas de $1.450^{\circ} \mathrm{C}$ e os tijolos cerâmicos, $1.000^{\circ} \mathrm{C}$, durante o processo de produção. A fabricação de tijolos cerâmicos, apesar de ser uma técnica já consolidada e que envolve pouca complexidade no seu processo de produção, causa grandes impactos ambientais, desde a fase da exploração das jazidas de argila até as fases de preparo da massa, moldagem dos blocos e queima. Portanto, diante desse cenário, o uso de materiais que envolvam baixo consumo energético, baixa geração de resíduos e poluentes, baixa emissão de $\mathrm{CO}_{2}$ na atmosfera e grande potencial de reincorporação na natureza, são uma alternativa para se atingir soluções mais sustentáveis para a construção civil, como é o caso das técnicas de construção em terra [2]

\subsection{Solo-cimento como material de construção}

Existem atualmente várias técnicas de construção em terra, que podem ser divididas em três grupos: monolítica, por unidades e por enchimento e revestimento [3]. A técnica de construção por unidades refere-se a préfabricação de blocos de adobe, blocos de terra comprimida e blocos de terra recortada ou extrudida [3]. A técnica em solo-cimento apresentada neste artigo enquadra-se neste grupo, onde os blocos são obtidos, por compressão, de uma mistura de terra, água e cimento.

O solo-cimento é um material já normatizado pela Associação Brasileira de Normas Técnicas (ABNT), possuindo vantagens que vão desde a fabricação até sua utilização no canteiro de obras. Proporciona redução no consumo de energia, principalmente por dispensar o processo de queima; redução da necessidade de transporte do produto, pois a terra local pode ser utilizada; e redução de resíduos na obra, além de, ao final da vida útil, poder ser mais facilmente incorporado no ambiente natural. Além disso, em geral, os equipamentos utilizados na sua produção são simples e de baixo custo, que pode contribuir para a autoconstrução, desde que haja um controle adequado quanto a dosagem dos materiais, a umidade de compactação, o processo de compactação e sobre os procedimentos de cura, o que requer um acompanhamento técnico especializado [2].

No entanto, ainda é necessário comprovar sua adequação em relação ao desempenho. Como o solo varia muito de local para local [4], é importante fortalecer uma cultura de avaliação de desempenho do material, com ensaios de laboratório apropriados, para proporcionar seu uso de forma segura e eficaz, desmistificando sua imagem de material de baixa qualidade.

Para a escolha da técnica de construção com terra adequada, é necessário o conhecimento da composição do solo, de suas propriedades e de seu comportamento, ou seja, composição granulométrica, plasticidade, retração, umidade e compactação [4], dentre outras. Para tal, vários ensaios já estão consolidados e podem ser divididos em dois grupos básicos: ensaios de campo e ensaios laboratoriais [5][6].

O solo-cimento, segundo a norma ABNT NBR 10833 [7], é a mistura homogênea composta de solo, cimento Portland e água em proporções estabelecidas por norma, que é comprimida través de uma prensa e endurecida, sem a necessidade de queima. O processo de fabricação dos tijolos constitui-se basicamente de preparação do solo, preparo da mistura, moldagem, cura e armazenamento.

Para a dosagem dos componentes da mistura, a norma ABNT NBR 10833 [7] recomenda a preparação de três traços diferentes de solo-cimento, bem como a moldagem de 20 blocos maciços ou vazados para cada 
um deles. Após a cura dos elementos, que leva no mínimo 14 dias, e com a manutenção deles úmidos nos primeiros 7 dias, eles devem ser enviados para análise laboratorial, para determinação da resistência à compressão e da absorção de água. O preparo da mistura pode ser realizado de forma manual ou mecânica, e pode-se incorporar outros materiais à mistura, como rejeitos industriais. As características do material resultante podem variar devido aos seguintes fatores: dosagem do cimento, natureza do solo, teor de umidade e grau de compactação [8]. A ABNT NBR 12023 [9] estabelece métodos para determinar a relação entre o teor de umidade e a massa específica aparente seca para misturas de solo-cimento.

O solo-cimento é um material de grande potencial para aplicação na construção de habitações populares, pois, de acordo com a ABCP [10], permite a redução dos custos em até 40\%, já que o material empregado em maior quantidade é o solo. CORDEIRO, CONCEIÇÃO e LIMA [11] destacam também que, por se tratar de alvenaria modular, há uma redução do desperdício e uma relativa eficiência na construção, devido ao fato dos blocos serem encaixados ou assentados com pouca quantidade de argamassa e, de possuírem furos internos, sem necessidade de cortes e quebras para a passagem de instalações hidráulicas e elétricas, dentre outras.

\subsection{Desempenho de sistemas construtivos}

A norma ABNT NBR 15575 [12] tem como objetivo regular e avaliar o desempenho de edificações habitacionais, independente da solução técnica utilizada, ou seja, dos seus materiais constituintes e do sistema construtivo. Seu enfoque está nas exigências dos usuários para a edificação habitacional e seus sistemas, quanto ao seu comportamento em uso e não na prescrição de como os sistemas são construídos. Estruturada em três áreas, aborda exigências relativas à segurança (estrutural, incêndio, uso e operação), habitabilidade (estanqueidade, desempenho térmico, desempenho acústico, desempenho lumínico, saúde, higiene e qualidade do ar, funcionalidade e acessibilidade, conforto tátil e antropodinâmico) e sustentabilidade (durabilidade, manutenibilidade e impacto ambiental).

A norma ABNT NBR 15575 [12] recomenda requisitos e critérios que devem ser observados pelos sistemas em avaliação. A avaliação pode ser feita através de ensaios experimentais. A parte 4 desta norma apresenta os requisitos e critérios mínimos para sistemas de vedações verticais externas (SVVE), escopo do estudo apresentado nesse artigo. A Tabela 1 apresenta a síntese de parâmetros da parte 4 que tratam de ensaios de desempenho para habitabilidade e sustentabilidade para SVVE aplicados ao sistema estudado, parede externa em blocos vazados de solo-cimento, pelo método de ensaio em laboratório.

Tabela 1: Itens da ABNT NBR 15575-4 para avaliação de desempenho, através de ensaio em laboratório, em corpos-deprova para fatores de habitabilidade e sustentabilidade

\begin{tabular}{l|l|l|l|l}
\hline $\begin{array}{l}\text { Exigência do } \\
\text { usuário }\end{array}$ & $\begin{array}{l}\text { Fator (item da nor- } \\
\text { ma) }\end{array}$ & Requisito (subitem) & Critério (subitem) & Método de ensaio \\
\hline Habitabilidade & $\begin{array}{l}\text { Estanqueidade (item } \\
10)\end{array}$ & $\begin{array}{l}\text { Infiltração de água } \\
\text { no SVVE (10.1) }\end{array}$ & $\begin{array}{l}\text { Estanqueidade à água da chuva } \\
(10.1 .1)\end{array}$ & Anexo C \\
\hline Habitabilidade & $\begin{array}{l}\text { Estanqueidade (item } \\
\text { Umidade no SVVE }\end{array}$ & $\begin{array}{l}\text { Estanqueidade à incidência } \\
\text { direta da água (10.2.1) }\end{array}$ & Anexo D \\
\hline Sustentabilidade & $\begin{array}{l}\text { Durabilidade e manu- } \\
\text { tenabilidade (item 14) }\end{array}$ & $\begin{array}{l}\text { Paredes externas } \\
(14.1)\end{array}$ & $\begin{array}{l}\text { Ação de calor e choque térmico } \\
(14.1 .1)\end{array}$ & Anexo E \\
\hline
\end{tabular}

Embora não tenha sido empregado neste estudo, o ensaio para a determinação de perda de massa, variação de umidade e variação de volume produzidos por ciclos de molhagem e secagem, normatizada pela ABNT NBR 13554 [13] é um ensaio de laboratório que deve ser considerado na caracterização do desempenho de blocos de solo-cimento.

HATTGE [14] realizou um estudo comparativo da permeabilidade de alvenarias de blocos cerâmicos e alvenarias de blocos de concreto, a fim de analisar seu desempenho quanto à penetração de umidade. Para isso, utilizou três métodos de ensaio para avaliação de estanqueidade à água em paredes: o método do cachimbo preconizado pelo Instituto de Pesquisas Tecnológicas de São Paulo (IPT), o método para verificação in situ da permeabilidade à água de fachadas e divisórias preconizado, também, pelo IPT e, o método para determinação da estanqueidade à água empregado pela Fundação de Ciência e Tecnologia do Estado do Rio Grande do Sul (CIENTEC). 
Os ensaios foram realizados utilizando-se três corpos de prova para cada sistema construtivo, com dimensões de 1,20 $\mathrm{m} \times 1,60 \mathrm{~m}$ (largura $\mathrm{x}$ altura). Foram ensaiados sem revestimento e com revestimento, composto por uma argamassa com proporção de 1:1:6 (cimento, cal e areia) nas espessuras de 1,5 cm na face exterior (submetida à água) e $1,0 \mathrm{~cm}$ na face interior.

Os métodos de verificação in situ da permeabilidade à água (IPT) e o método para determinação da estanqueidade à água (CIENTEC), utilizados pelo autor, são bem similares aos ensaios normatizados pela ABNT NBR 15575 [12] e aos empregados no estudo dos blocos de solo-cimento deste artigo.

O ensaio de verificação in situ da permeabilidade consistiu em submeter os corpos-de-prova à presença de água com pressão constante por meio de uma câmara em formato de caixa acoplada em uma das faces da parede com uma bureta graduada para manutenção da pressão constante no interior da câmara e para medida do volume de água infiltrado na parede. Nos blocos, tanto cerâmico como de concreto, sem revestimento, não foi possível realizar leitura na bureta graduada, pois houve grande infiltração de água nos corpos-deprova. Os blocos cerâmicos com revestimento sofreram infiltração de $2.925 \mathrm{~cm}^{3}$ e os blocos de concreto com revestimento sofreram infiltração de $3.435 \mathrm{~cm}^{3}$, valores bem maiores se comparados ao sistema estudado. [14]

O ensaio para determinação da estanqueidade à água da chuva consistiu em submeter os corpos-deprova à película de água com pressão pneumática sobre a superfície, através de uma câmara estanque ao ar de formato prismático nas dimensões de $90 \mathrm{~cm}$ x $110 \mathrm{~cm}$. O ensaio foi dividido em duas etapas, na primeira, a película de água é aplicada sem pressão, e na segunda, com pressão de $260 \mathrm{~Pa}$. Em ambas as etapas os corpos-de-prova foram avaliados visualmente, através da marcação das manchas de umidade na face oposta a aspersão de água, nos tempos de 5, 15, 30, 60, 90, 120 e 150 minutos, para a primeira etapa, e, de 5, 15, 30, 60, 90 e 120, para a segunda etapa.[14] Diferentemente do presente estudo, que submeteu as paredes por 7 horas à aspersão de água com pressão de $50 \mathrm{~Pa}$, conforme estabelece a norma ABNT NBR 15575 - Parte 4 (Anexo D).

HATTGE [14] observou que, tanto nas paredes de bloco cerâmicos, como nas de concreto, sem revestimento, o desempenho relativo à estanqueidade à água da chuva não foi satisfatório. A área com manchas de umidade nos corpos-de-prova ao final dos testes foi de $1 / 3$ da área, eu seja de aproximadamente 33,3\%. Os corpos-de-prova, de ambos os sistemas de vedação, com revestimento, não apresentaram nenhuma mancha de umidade.

RODRIGUES [15] também analisou o desempenho quanto à permeabilidade à água, seguindo as especificações da norma ABNT NBR 15575 [12]. Testou, na mesma parede de blocos cerâmicos, diferentes tipos de acabamento (sem revestimento, com selador acrílico, com selador acrílico mais tinta PVA, com selador acrílico mais tinta acrílica, com selador acrílico mais textura acrílica, com selador acrílica mais textura acrílica e tinta PVA e com selador acrílico mais textura acrílica e tinta acrílica) e argamassa de revestimento (proporção 1:1:6, industrializada e proporção de 1:2:9). Nos tempos de 0 a 60 minutos, nenhum dos corposde-prova atendeu ao limite da Norma.

OLIVEIRA, FONTENELLE e MITIDIERI FILHO [16] realizaram ensaios de ação de calor e choque térmico conforme a ABNT NBR 15575 [12] em duas paredes estruturadas com perfil de aço conformados a frio e fechamento em chapas cimentíceas fixadas aos perfis com parafusos. A norma determina que não sejam verificadas fissuras e deslocamentos horizontais no corpo-de-prova que possam comprometer o desempenho do sistema de vedação externo. Foram ensaiadas duas conformações da mesma parede, porém variando tratamento das juntas entre placas de vedação, dimensões do corpo-de-prova e vínculo externo (restrição de movimento lateral da parede). As paredes diferiram no comprimento do trecho ensaiado (1,20m e $2,40 \mathrm{~m}$ com restrição na movimentação lateral), mantendo a mesma altura $(2,60 \mathrm{~m})$. Os resultados indicaram que a parede 1 (1,20 de comprimento sem restrição) atendeu aos critérios da norma, mas a parede 2 (2,40m de comprimento com restrição) não atendeu, indicando que o ensaio preconizado pela ABNT NBR 15575-4 pode não representar o desempenho real da parede.

VARISCO [17] avaliou um sistema de vedação vertical externo (SVVE) formado por blocos de concreto celular autoclavado sem função estrutural segundo ensaios de ação de calor e choque térmico indicados na ABNT NBR 15575, parte 4. As dimensões do corpo-de-prova eram 1,80m $\times 2,75 \mathrm{~m} \times 0,10 \mathrm{~m}$. Foi possível a visualização de fissuras de $0,1 \mathrm{~mm}$ nas duas faces do corpo-de-prova no terceiro ciclo de aquecimento e resfriamento e o deslocamento horizontal foi inferior ao critério mínimo estabelecido na norma. Também realizou o ensaio de estanqueidade à água da chuva para a mesma parede, antes e depois do ensaio de ação de calor e choque térmico, e verificou que não houve manchas na face oposta do SVVE, atingindo o nível de desempenho Intermediário ou Superior, conforme a ABNT NBR 15575. 


\subsection{Objetivo}

O artigo apresenta a avaliação de desempenho de um SVVE, composto por blocos vazados de solo-cimento, sem função estrutural, para edificações habitacionais, seguindo determinações da norma ABNT NBR 15575 [12], focando nas exigências de habitabilidade e sustentabilidade.

\section{MATERIAIS E MÉTODOS}

O objeto de estudo é um sistema construtivo composto por blocos vazados de solo-cimento, nas dimensões de $25 \mathrm{~cm} \times 7 \mathrm{~cm} \times 12,5 \mathrm{~cm}$, de acordo com a definição da ABNT NBR 10834 [18]. A Figura 1 ilustra o bloco estudado.

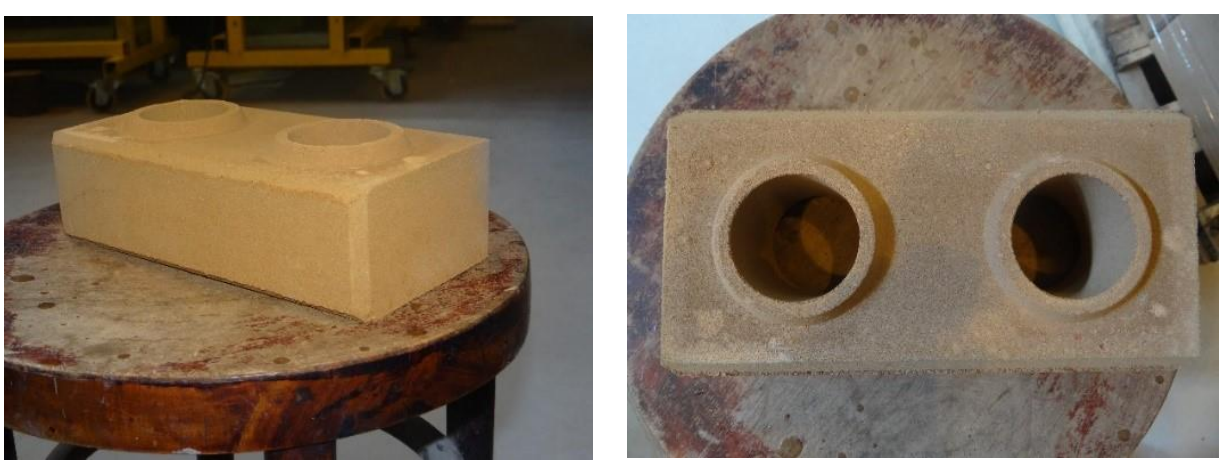

Figura 1: Bloco de solo-cimento submetido à avaliação.

\subsection{Caracterização do solo}

Para a caracterização do solo utilizado na fabricação dos blocos, foi realizada a determinação do limite de liquidez conforme a ABNT NBR 6459 [19], a determinação do limite de plasticidade conforme a norma ABNT NBR 7180 [20] e a análise granulométrica por peneiramento conforme a ABNT NBR 7181 [21].

As características do solo, obtidas nos ensaios, são expressas na Tabela 2, sendo estes, comparados com as determinações da norma ABNT NBR 10833 [7], que trata dos procedimentos para fabricação de tijolo maciço e bloco vazado de solo-cimento com a utilização de prensa hidráulica. É possível observar que um dos requisitos desta norma não foi atendido, pois a porcentagem passante na peneira ${ }^{\circ} 200(0,075 \mathrm{~mm})$ ficou abaixo do limite estabelecido, indicando um baixo teor de argila e silte na sua composição. Os demais requisitos (porcentagem passando na peneira $\mathrm{n}^{\circ} 4$, limite de liquidez e limite de plasticidade) foram atendidos, sendo que a partir do resultado do limite de liquidez, pode-se concluir que o solo em análise é arenoso [5], o que o torna mais poroso e permeável, características que provavelmente irão influenciar na estanqueidade e permeabilidade do material produzido com este solo.

Tabela 2: Caracterização do solo segundo a ABNT NBR 10833.

\begin{tabular}{c|l|c|c}
\hline NBR & REQUISITO ABNT NBR $\mathbf{1 0 8 3 3}$ & CRITÉRIO & RESULTADO OBTIDO \\
\hline 6459 & Limite de liquidez & $\leq 45 \%$ & $23,8 \%$ \\
\hline 7180 & Limite de plasticidade & $\leq 18 \%$ & $18,0 \%$ \\
\hline 7181 & $\%$ passante na peneira $\mathrm{n}^{\circ} 4(4,75 \mathrm{~mm})$ & $100 \%$ & $100 \%$ \\
\hline 7181 & $\%$ passante na peneira $\mathrm{n}^{\circ} 200(0,075 \mathrm{~mm})$ & $10 \%$ a $50 \%$ & $1,5 \%$ \\
\hline
\end{tabular}

O cimento adicionado ao solo para produção dos blocos foi CP V ARI, sendo a mistura realizada mecanicamente na proporção de $87 \%$ de solo e $13 \%$ de cimento com adição de água. Após prensagem, os elementos foram curados ao ar durante 28 dias, sendo que, nos primeiros 7 dias, foram mantidos úmidos por molhagens sucessivas e cobertos por lona plástica. A quantidade de água acrescentada à mistura era depende da umidade do solo no momento da fabricação e foi dosada pelo fabricante dos blocos de solo-cimento.

\subsection{Corpos-de-prova}

O sistema construtivo dos corpos-de-prova consistiu em blocos vazados de solo-cimento encaixados e assentados com massa polimérica, grauteados nas extremidades laterais e no centro, formando colunas, e a $0,98 \mathrm{~m}$ da base inferior e na extremidade superior, formando vigas, com armadura simples de ferro $8 \mathrm{~mm}$, rejuntados 
após 24 horas do grauteamento com argamassa cimentícia e impermeabilizados com três camadas de resina acrílica após 28 dias da execução, sendo o período de secagem da resina de 120 horas, sendo o rejunte e a impermeabilização apenas na face considera externa do elemento, conforme pode ser visualizado na Figura 2.

Foram edificadas duas paredes em escala real $(1,25 \mathrm{~m} \times 2,38 \mathrm{~m})$, que para fins deste estudo foram nomeadas de Parede A e Parede B.
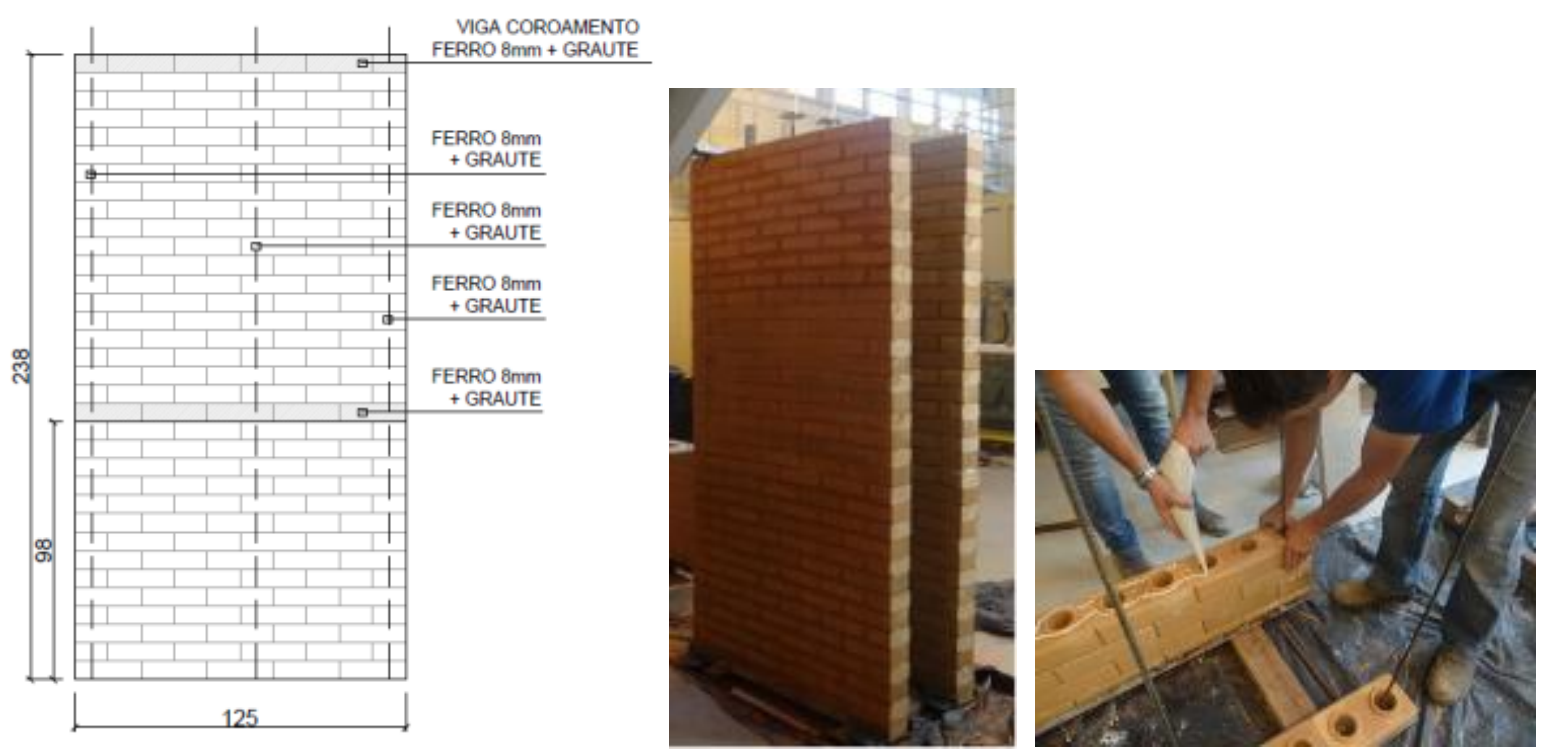

Figura 2: Esquema da construção do corpo-de-prova e imagem dos corpos de prova usados no ensaio.

\subsection{Ensaios realizados}

As dimensões dos corpos-de-prova e os ensaios foram realizados seguindo as determinações da ABNT NBR 15575 [12], que trata do desempenho de edificações habitacionais, através das exigências de habitabilidade e sustentabilidade.

Em relação as exigências de habitabilidade, analisou-se o fator estanqueidade à água por meio dos ensaios de estanqueidade à água da chuva e permeabilidade à água, e, quanto às exigências de sustentabilidade, analisou-se os fatores de durabilidade, através da realização do ensaio de ação de calor e choque térmico. $\mathrm{Na}$ Tabela 3, apresenta-se de forma esquemática o desenvolvimento dos ensaios e os respectivos corpos-deprova ensaiados em cada situação.

Tabela 3: Planejamento dos ensaios.

\begin{tabular}{l|l|l|l}
\hline EXIGÊNCIA & REQUSISTO DE DESEMPENHO & ENSAIO & CORPO-DE-PROVA \\
\hline Habitabilidade & Estanqueidade à água da chuva & Estanqueidade à água da chuva & $\begin{array}{l}\text { Parede A } \\
\text { Parede B }\end{array}$ \\
\hline Habitabilidade & Estanqueidade à água & Permeabilidade à água & Parede B \\
\hline Sustentabilidade & Durabilidade & Ação de calor e choque térmico & $\begin{array}{l}\text { Parede A } \\
\text { Parede B }\end{array}$ \\
\hline
\end{tabular}

\subsubsection{Estanqueidade à água da chuva}

O ensaio de estanqueidade à água da chuva consistiu em submeter, durante 7 horas ininterruptas, a face externa do corpo-de-prova do SVVE a uma vazão de água de $31 / \mathrm{min} / \mathrm{m}^{2}$, criando uma película homogênea e contínua, com a aplicação simultânea de uma pressão pneumática de $50 \mathrm{~Pa}$ sobre essa face de. Foram registrados, para cada corpo-de-prova, o tempo de ensaio quando do aparecimento da primeira mancha de umidade na face oposta à aspersão da água (detectada visualmente) e a porcentagem da área da mancha de umidade ao final do ensaio em relação à área total da face não exposta a aspersão da água.

Segundo a norma ABNT NBR 15575, parte 4 [12], os SVVE da edificação habitacional "devem per- 
manecer estanques e não apresentar infiltrações que proporcionem borrifamentos, ou escorrimentos ou formação de gotas de água aderentes na face interna”. Podem ocorrer pequenas manchas de umidade, com percentual máximo de $10 \%$, para 7 horas, para edificação térrea e paredes sem função estrutural. O percentual é calculado a partir da área total da parede, considerando-se a mancha de umidade na face oposta de incidência de água.

\subsubsection{Permeabilidade à água}

O ensaio de permeabilidade à água (Figura 3), realizado de acordo com a ABNT NBR 15575 [12], consistiu em submeter um trecho de parede à presença de água, com pressão constante, por meio de uma câmara em formato de caixa acoplada à parede, com dimensões internas de $34 \mathrm{~cm} \mathrm{x} 16 \mathrm{~cm}$ (largura x altura). Para manter a pressão constante no interior da câmara e para medir o volume de água infiltrado no corpo-de-prova, foi utilizada uma bureta graduada em centímetros cúbicos. Esta bureta foi encaixada na câmara, de maneira que sua boca tangenciasse o nível de água no seu interior, isso para que, quando da infiltração de água no corpode-prova, o mesmo volume de água infiltrada fosse reposto pela água contida na bureta, mantendo constante o nível de água no interior da câmara e permitindo a quantificação da água infiltrada. Os níveis da água foram registrados no início do processo e aos 30, 60, 120, 240, 360 e 1.440 minutos de ensaio.

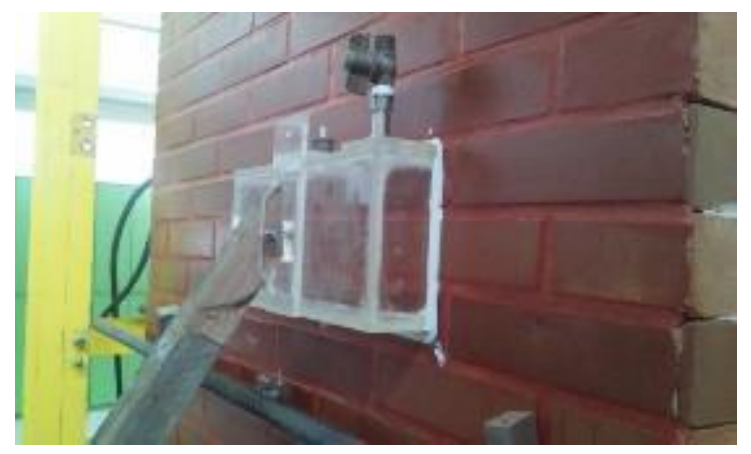

Figura 3: Ensaio de permeabilidade à água.

\subsubsection{Ação de Calor e Choque Térmico}

O ensaio de ação de calor e choque térmico, realizado de acordo com a norma ABNT NBR 15575 [12], consistiu em submeter cada corpo-de-prova a 10 ciclos sucessivos de calor proveniente de fonte radiante e imediato resfriamento por meio de jatos de água à temperatura uniforme de $15{ }^{\circ} \mathrm{C}$, com o objetivo de simular as condições de exposição das fachadas durante a sua vida útil, ou seja, as variações de temperatura e umidade. Junto à face exposta à ação de calor e choque térmico, foram instalados cinco termopares conectados a um Fieldlogger (Figura 4), com o objetivo de registrar as variações de temperatura, e na face oposta ao aquecimento e resfriamento, foi instalado um deflectômetro eletrônico, no centro do corpo de prova, na face não exposta ao aquecimento e resfriamento, com a finalidade de monitorar os deslocamentos horizontais instantâneos no decorrer dos ciclos.

A ABNT NBR 15575 [12] recomenda que os SVVE não apresentem deslocamento horizontal instantâneo, que é medido após 45 minutos da estabilização da temperatura, no plano perpendicular ao corpo de prova, superior a h/300, onde h é a altura do corpo de prova; e não apresentem ocorrência de falhas, como fissuras, destacamentos, empolamentos, descoloramentos e outros danos que possam comprometer a utilização do sistema de vedação vertical externo 

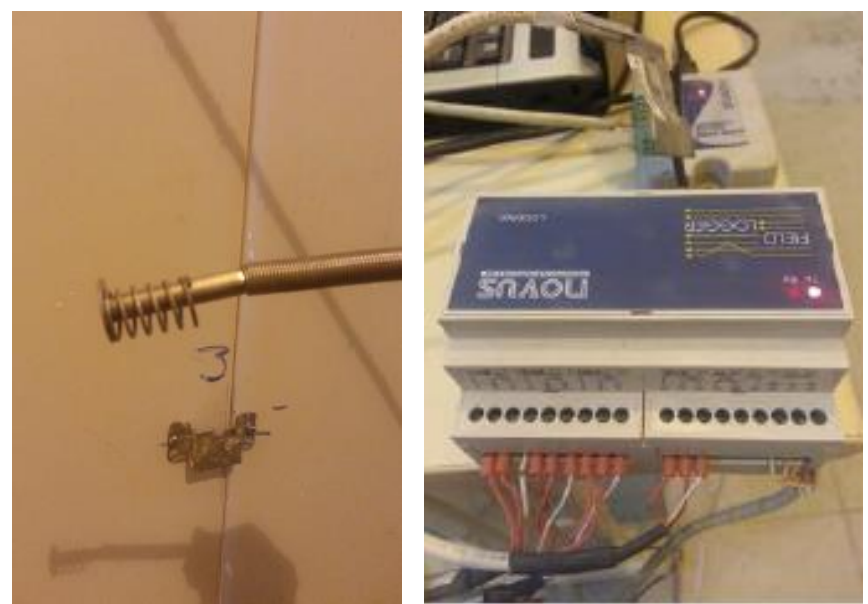

Figura 4: Termopar e Fieldlogger para aquisição de dados.

\section{RESULTADOS E DISCUSSÕES}

A seguir, serão apresentados os resultados dos ensaios realizados.

\subsection{Habitabilidade - ensaio de estanqueidade à água da chuva}

Considerando a área dos corpos-de-prova, 2,975 $\mathrm{m}^{2}$ e dimensões 1,25 m × 2,38 $\mathrm{m}$ (largura $\mathrm{x}$ altura), a área máxima de manchas de umidade na face oposta à incidência de água, após a realização do ensaio, foi de $0,2975 \mathrm{~m}^{2}$. Como ambos os corpos-de-prova foram submetidos ao ensaio de estanqueidade à água de chuva antes e depois do ensaio de ação de calor e choque térmico, para fins de nomenclatura, os ensaios da parede A foram denominados Ensaio de Estanqueidade 1 da Parede A (EE1A) e Ensaio de Estanqueidade 2 da Parede A (EE2A), referente ao primeiro e ao segundo ensaio de estanqueidade, respectivamente. Da mesma maneira a parede B foi subdividida em Ensaio de Estanqueidade 1 da Parede B (EE1B) e Ensaio de Estanqueidade 2 da parede $B$ (EE2B).

A análise dos corpos-de-prova foi realizada visualmente e as áreas de manchas de umidade foram calculadas tendo por base as dimensões de um bloco de $0,25 \mathrm{~m} \times 0,125 \mathrm{~m} \times 0,07 \mathrm{~m}$ (comprimento $\mathrm{x}$ largura $\mathrm{x}$ altura). Na Tabela 4, apresentam-se os resultados obtidos nesse ensaio.

Tabela 4: Resultado de ensaio de estanqueidade à água da chuva.

\begin{tabular}{l|l|l|l}
\hline $\begin{array}{l}\text { ENSAIO / CORPO DE } \\
\text { PROVA }\end{array}$ & $\begin{array}{l}\text { ÁREA MOLHADA DA FACE } \\
\text { INTERNA }\end{array}$ & $\begin{array}{l}\text { ALTERAÇÃo NA FACE } \\
\text { EXTERNA }\end{array}$ & $\begin{array}{l}\text { MÁXIMA ÁREA MOLHADA } \\
\text { PERMITIDA }\end{array}$ \\
\hline EE1A & $0,11 \mathrm{~m}^{2}$ & Não & $0,2975 \mathrm{~m}^{2}$ \\
\hline EE2A & $0,23 \mathrm{~m}^{2}$ & Não & $0,2975 \mathrm{~m}^{2}$ \\
\hline EE1B & $0,12 \mathrm{~m}^{2}$ & Mancha em um bloco & $0,2975 \mathrm{~m}^{2}$ \\
\hline EE2B & $0,14 \mathrm{~m}^{2}$ & não & $0,2975 \mathrm{~m}^{2}$ \\
\hline
\end{tabular}

Em todos os corpos-de-prova observou-se a ocorrência de uma mancha de umidade contínua na base, devido à falta de vedação da base de apoio da parede, indicando que sem a impermeabilização com resina acrílica, provavelmente, o bloco não seria estanque à água.

Concluiu-se, com base nos resultados apresentados acima, que todos os corpos-de-prova, tanto antes como após o ensaio de ação de calor e choque térmico, estão dentro dos limites estabelecidos pela norma para a exigência de habitabilidade, fator estanqueidade, expresso pelo ensaio de estanqueidade à água da chuva (Figura 5). 


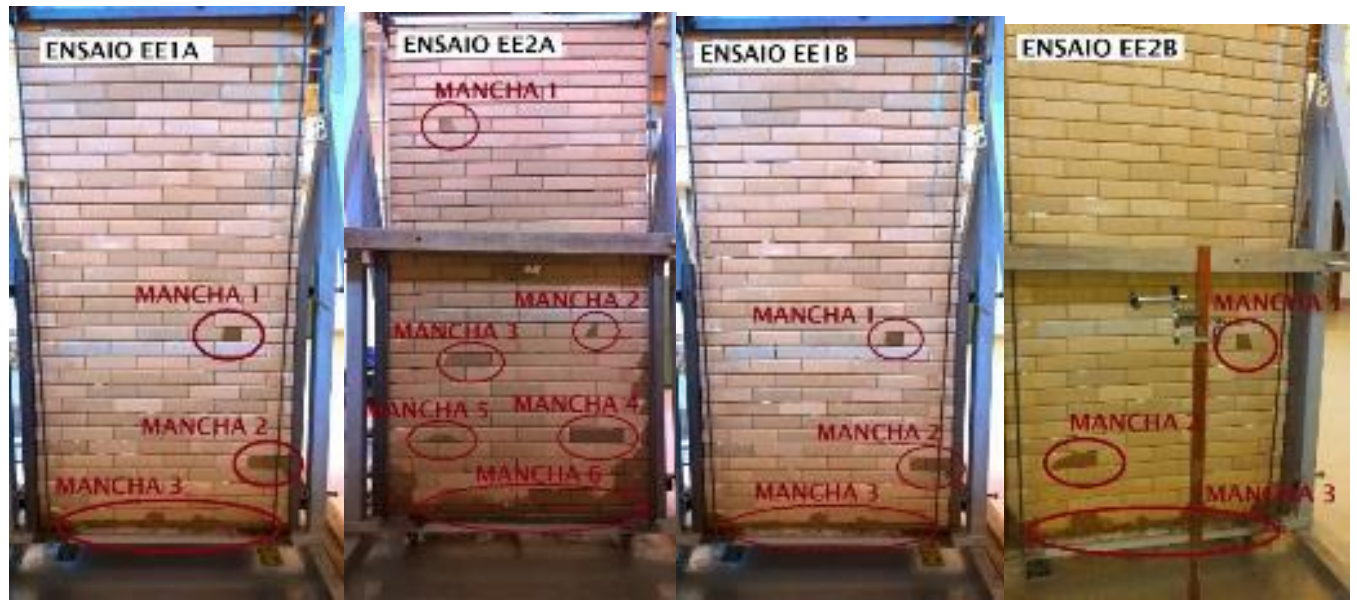

Figura 5: Parede A - Análise visual da face interna após o primeiro (EE1A) e segundo (EE2A) ensaio de estanqueidade, respectivamente; Parede B - Análise visual da face interna após o primeiro (EE1B) e segundo (EE2B) ensaio de estanqueidade, respectivamente.

Comparando-se os resultados obtidos com estudos de HATTGE [14] para sistemas de vedação compostos por blocos cerâmicos e blocos de concreto, estes apresentaram melhor desempenho à estanqueidade à água da chuva que o sistema de blocos de solo-cimento. Este comportamento provavelmente ocorreu devido a aplicação de revestimento argamassado, tanto na face exterior com interior, das paredes. Observa-se que, mesmo sem a aplicação deste revestimento argamassado nas paredes desta pesquisa, as quais foram impermeabilizadas apenas com a resina acrílica na face exterior, o sistema analisado alcançou desempenho satisfatório. Entretanto, esse desempenho poderia ser questionável no decorrer dos anos, principalmente devido à ação de chuvas, incidência solar e falta de manutenção, de forma que, sugere-se pesquisas futuras que visem a melhoria desse sistema construtivo, como por exemplo, avaliação quando aplicado revestimento argamassado nas suas faces seguido de pintura impermeabilizante.

\subsection{Habitabilidade - ensaio de permeabilidade à água}

Segundo a norma ABNT NBR 15575 - Parte 4 [12], a quantidade de água que pode penetrar no SVVE não deve ser superior a $3 \mathrm{~cm}^{3}$, por um período de $24 \mathrm{~h}$, na área exposta.

A Tabela 5 apresenta os resultados deste ensaio, onde verifica-se que a parede ensaiada (Parede B) não atendeu ao limite da norma para a exigência de habitabilidade, fator estanqueidade, expresso pelo ensaio de permeabilidade à água.

Tabela 5: Resultado de ensaio de permeabilidade à água.

\begin{tabular}{l|c|c|c|c|c|c|c}
\hline TEMPO (MIN) & 00 & 30 & 60 & 120 & 240 & 360 & $\begin{array}{c}1440 \\
(24 \mathrm{~h})\end{array}$ \\
\hline VOLUME ÁGUA INFILTRADA (CM3) & 0,0 & 36,0 & 11,6 & 17,8 & 18,0 & 16,5 & 54,0 \\
\hline VOLUME TOTAL (CM3) & \multicolumn{7}{|c|}{153,9} \\
\hline
\end{tabular}

Comparando-se este resultado com o obtido com HATTGE [14], em paredes de $120 \mathrm{~cm}$ x $160 \mathrm{~cm} \times$ $14 \mathrm{~cm}$ e com mesma área de aplicação de água $(16 \mathrm{~cm} \times 34 \mathrm{~cm})$, observa-se que em blocos cerâmicos com revestimento argamassado, a infiltração atingiu 2.925,00 $\mathrm{cm}^{3}$, e em blocos de concreto com revestimento argamassado, a infiltração atingiu $3.435,00 \mathrm{~cm}^{3}$, valores bem maiores se comparados ao sistema estudado. Já em RODRIGUES [15], foram ensaiados blocos cerâmicos sem revestimento argamassado, mas impermeabilizados com diferentes tipos de impermeabilizantes, notando-se que todas os corpos-de-prova também não conseguiram atingir o limite especificado pela norma. 


\subsection{Sustentabilidade - ensaio de ação de calor e choque térmico}

Os corpos-de-prova possuíam altura de $2.380 \mathrm{~mm}$, de modo que o deslocamento horizontal instantâneo máximo permito (h/300, onde h é a altura do corpo-de-prova) era de $8,0 \mathrm{~mm}$.

Na Tabela 6 são apresentados os deslocamentos da parede A e B, sendo em cada ciclo, Dhi o deslocamento horizontal instantâneo medido após 45 minutos da estabilização da temperatura em $80 \pm 3{ }^{\circ} \mathrm{C}$; Dhr o deslocamento horizontal residual medido após o resfriamento da parede a temperatura de $20 \pm 5{ }^{\circ} \mathrm{C}$; e, Dh o deslocamento horizontal total sofrido pela parede.

Tabela 6: Deslocamentos horizontais das paredes A e B.

\begin{tabular}{l|l|l|l|l|l|l|l}
\hline \multicolumn{7}{l}{ PAREDE A } & \multicolumn{7}{l}{ PAREDE B } \\
\hline CICLOS & Dhi $(\mathbf{m m})$ & Dhr $(\mathbf{m m})$ & Dh $(\mathbf{m m})$ & CICLOS & Dhi $(\mathbf{m m})$ & Dhr $(\mathbf{m m})$ & Dh (mm) \\
\hline 1 & 0,85 & 0,21 & 0,64 & 1 & 0,95 & 0,43 & 0,52 \\
\hline 2 & 0,60 & 0,18 & 0,63 & 2 & 0,23 & 0,16 & 0,39 \\
\hline 3 & 0,51 & 0,03 & 0,66 & 3 & 0,34 & 0,16 & 0,50 \\
\hline 4 & 0,64 & 0,03 & 0,64 & 4 & 0,66 & 0,10 & 0,56 \\
\hline 5 & 0,73 & 0,03 & 0,73 & 5 & 0,52 & 0,04 & 0,48 \\
\hline $7 *$ & 1,03 & 0,11 & 0,95 & $6 * *$ & 1,02 & 0,51 & 0,51 \\
\hline 8 & 0,95 & 0,25 & 0,70 & 7 & 0,40 & 0,14 & 0,64 \\
\hline 10 & 0,59 & 0,33 & 0,51 & 8 & 0,47 & 0,04 & 0,43 \\
\hline
\end{tabular}

*os ciclos 7, 8, 9 e 10 foram realizados em dia diferente dos primeiros ciclos. A temperatura registrada para o dia foi de aproximadamente $10^{\circ} \mathrm{C}$, portanto um dia frio; **os 5 primeiros ciclos foram realizados em um dia; os ciclos 6,7 e 8 em outros; e os ciclos 9 e 10 em outro. A temperatura registrada para o dia foi de aproximadamente $10^{\circ} \mathrm{C}$, portanto um dia frio.

A partir da análise dos resultados, tem-se que o deslocamento instantâneo máximo (Dhi) da parede A foi de $1,03 \mathrm{~mm}$ e da parede $\mathrm{B}$ foi de $1,02 \mathrm{~mm}$, ambos atendendo o limite máximo preconizado pela ABNT NBR 15575 [12], que para estes corpos-de-prova era de 8,00 $\mathrm{mm}$.

A Figura 6 ilustra a representação esquemática dos deslocamentos das paredes A e B, respectivamente. Observa-se que em todos os ciclos, a Parede A praticamente voltou à sua posição inicial após o resfriamento à $20 \pm 5{ }^{\circ} \mathrm{C}$, mostrando que este corpo-de-prova não sofreu deslocamentos horizontais residuais (Dhr) significativos quando exposto à ação de calor e choque térmico. Comportamento similar foi observado na Parede $\mathrm{B}$, onde na maioria dos ciclos o corpo-de-prova praticamente voltou à sua posição inicial após o resfriamento à $20 \pm 5^{\circ} \mathrm{C}$, exceto nos ciclos 1 e 6 onde houve um deslocamento horizontal residual (Dhr) pronunciado após o resfriamento da parede a temperatura de $20 \pm 5^{\circ} \mathrm{C}$. Na Parede B também se observa a diminuição dos valores de deslocamento totais (Dh) em relação à Parede $\mathrm{A}$. 


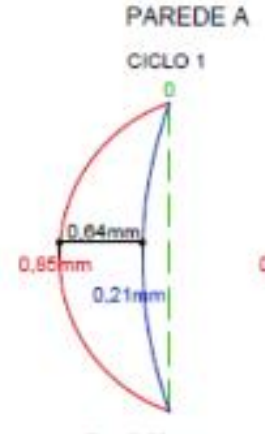

Dhi=0,85 mm Ohro 0,21 mm

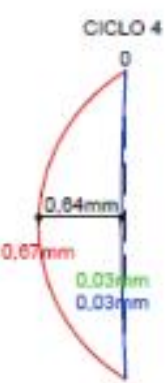

Dhim0,84 mm Dhre0.03 mm Dhr=0.03 mm
Dh $=0.64 \mathrm{~mm}$

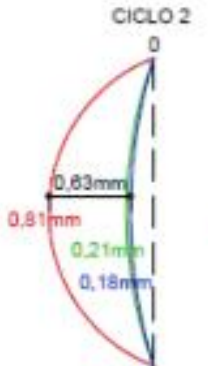

Dhi $=0,60 \mathrm{~mm}$ Dhrmo, $18 \mathrm{~mm}$ Dh $=0.03 \mathrm{~mm}$

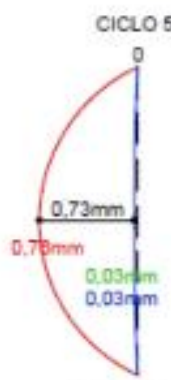

Dhi=0,73 mm Dhre0.03 mm Dh $=0,73 \mathrm{~mm}$

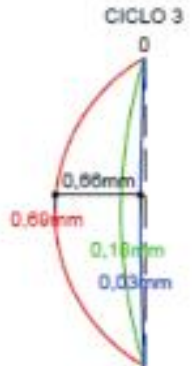

Ohi=0.51 mm Dhrm0.03 mm Dh $=0.06 \mathrm{~mm}$
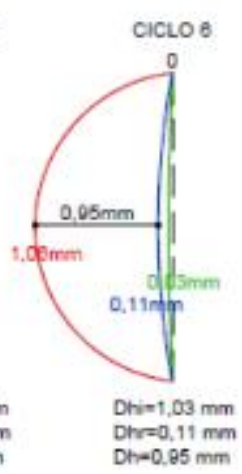

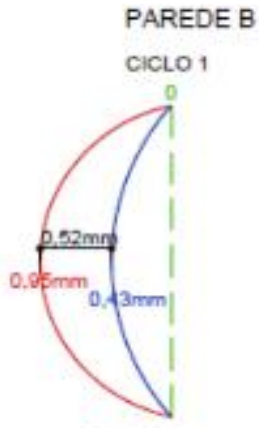

Dhi $=0.05 \mathrm{~mm}$ $\mathrm{Dhr}=0.43 \mathrm{~mm}$ Dh $=0.52 \mathrm{~mm}$

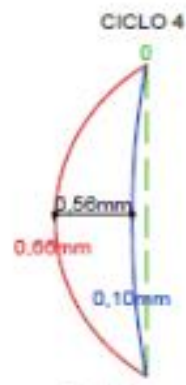

Dh $=0,06 \mathrm{~mm}$ Dh $=0,10 \mathrm{~mm}$ $\mathrm{Dh}=0.58 \mathrm{~mm}$

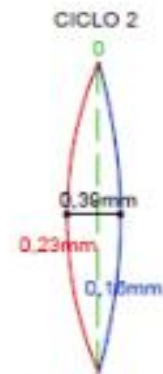

Dh $=0.23 \mathrm{~mm}$ Dhr $=0,16 \mathrm{~mm}$
$D h=0.30 \mathrm{~mm}$ Dh $=0.30 \mathrm{~mm}$

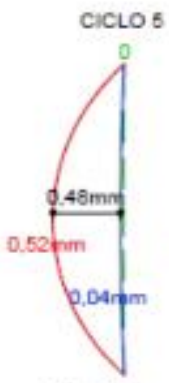

Dhe $=0.52 \mathrm{~mm}$ Dhr $=0.04 \mathrm{~mm}$ Dh=0.48 mm

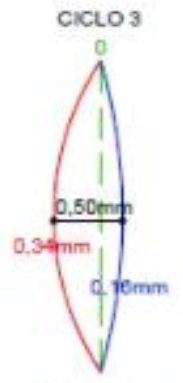

$\mathrm{Dhv}=0.34 \mathrm{~mm}$ Dhr $=0,16 \mathrm{~mm}$
Dh $=0,50 \mathrm{~mm}$

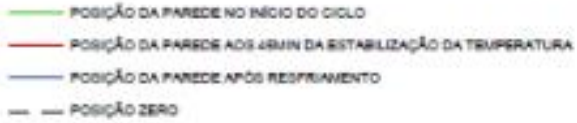

Figura 6: Representação esquemática dos primeiros 6 ciclos de resfriamento das paredes A e B respectivamente.

Após o término do ensaio, uma análise visual indicou que os corpos-de-prova não apresentaram ocorrência de falhas, como fissuras, destacamentos, empolamentos, descoloramentos e outros danos que pudessem comprometer a utilização do sistema de vedação vertical externo.

\section{CONCLUSÃO}

Os resultados indicam que o SVVE avaliado atendeu a exigência de habitabilidade, fator estanqueidade, por meio do ensaio de estanqueidade à chuva, pois os parâmetros indicados pela ABNT NBR 15575 [12] foram atendidos, inclusive após o ensaio de ação de calor e choque térmico, demonstrando que possivelmente o sistema continuaria estanque com a ação do tempo por um determinado período. Entretanto, devido ao aparecimento de uma mancha contínua na base, provavelmente ocasionada pela ausência de vedação neste local sugere que a mesma parede sem impermeabilização perderia as suas propriedades de estanqueidade.

O SVVE também atendeu a exigência de sustentabilidade, para o requisito de durabilidade, através do Ensaio de ação de calor e choque térmico, pois novamente os parâmetros indicados pela ABNT NBR 15575 [12] foram atendidos em todos os ciclos. Verificou-se que, em quase todos os ciclos, os corpos-de-prova praticamente voltaram à sua posição inicial após o resfriamento à $20 \pm 5^{\circ} \mathrm{C}$, demonstrando que o SVVE ensaiado não sofreu deslocamento horizontal significativo quando exposta à ação do calor.

Entretanto, o SVVE não atendeu à ABNT NBR 15575 [12] para a exigência de habitabilidade, requisito de estanqueidade à água, expresso pelo ensaio de permeabilidade à água.

Esses resultados permitem concluir que o sistema construtivo avaliado possui grande potencial para ser utilizado como SVVE, mas que precisa ser aprimorado, visto que um dos fatores avaliados, estanqueidade à água da chuva, não foi atendido. Salienta-se, ainda, que a referida norma determina que outros indicadores de desempenhos sejam avaliados, tais como segurança estrutural, segurança contra incêndio, conforto térmi- 
co, conforto acústico, para um adequado entendimento das características e do comportamento do sistema em análise.

\section{AGRADECIMENTOS}

Agradecemos à toda equipe do Laboratório de Ensaios e Modelos Estruturais (LEME) da UFRGS pelo auxílio antes, durante e após os ensaios.

\section{BIBLIOGRAFIA}

[1] CBCS, Conselho Brasileiro de Construção Sustentável, Aspectos da Construção Sustentável no Brasil e Promoção de Políticas Públicas, 2014, http://www.cbcs.org.br. Acessado em março de 2017.

[2] MELO, A.B. BARBOSA, N.P., LIMA, M.R.F., et al.,"Desempenho estrutural de protótipo de alvenaria construída com blocos de terra crua estabilizada", Revista Ambiente Construído, v. 11, n. 2, pp. 111-124, 2011.

[3] TORGAL, F. P., JALALI, S., A sustentabilidade dos materiais de construção. Minho (Portugal): TecMinho, 2010 .

[4] PONTE, M. M. C. C., Arquitetura de Terra: o desenho para a durabilidade das construções, Dissertação de M.Sc, Universidade de Coimbra,Coimbra, Portugal, 2012.

[5] NEVES, C. M. M., FARIA, O.B., ROTONDARO, R., et al., Seleção de solos e métodos de controle na construção com terra, Rede Ibero-americana PROTERRA, 2010, http://www.redproterra.org. Acessadoemmarço de 2014.

[6] TORGAL, F. P., JALALI, S., “Construção em terra: o passado, o presente e o futuro”,Arte \& Construção, outubro,pp. 52-56, 2009, http://repositorium.sdum.uminho.pt/bitstream/1822/10742/1/Const.\%20Terra.pdf. Acessado em junho 2017.

[7] ABNT, NBR 10833: Fabricação de tijolo e bloco de solo-cimento com utilização de prensa manual ou hidráulica - Procedimento, Rio de Janeiro, ABNT - Associação Brasileira de Normas Técnicas, 2013.

[8] LIMA, F. X. R. F., Blocos de terra compactada de solo-cimento com resíduo de argamassa de assentamento e revestimento: caracterização para uso em edificações, Tese de D.Sc., Universidade de Brasília, Brasília, 2013.

[9] ABNT, NBR 12023: Solo-cimento - Ensaio de compactação, Rio de Janeiro, ABNT - Associação Brasileira de Normas Técnicas, 2012.

[10] ABCP, Associação Brasileira de Cimento Portland, Dosagem das Misturas de Solo-Cimento: Normas de Dosagem e Métodos de Ensaio, Estudo Técnico 35, São Paulo, 1986.

[11] CORDEIRO, M. E. V. M., CONCEIÇÃO, P. M., LIMA, T. V.,“A educação ambiental e o uso do solocimento", Revista Vértices, v.8, n.1, 2006.

[12] ABNT, NBR 15575: Edificações habitacionais - Desempenho, Rio de Janeiro, ABNT - Associação Brasileira de Normas Técnicas, 2013.

[13] ABNT, NBR 13554: Solo-cimento - Ensaio de durabilidade por molhagem e secagem, ABNT - Associação Brasileira de Normas Técnicas, 2012.

[14] HATTGE, A. F., Estudo comparativo sobre a permeabilidade das alvenarias em bloco cerâmicos e alvenarias em bloco de concreto, Dissertação de M.Sc., Universidade Federal do Rio Grande do Sul, Porto Alegre, 2004.

[15] RODRIGUES, A. H., Estanqueidade de alvenaria revestida com diferentes argamassas e acabamentos: aplicação da NBR 15575-4/2008, Monografia de Eng. Civil, Universidade Federal do Rio Grande do Sul, Porto Alegre, 2010.

[16] OLIVEIRA, L. A., FONTENELLE, J. H., MITIDIERI FILHO, C. V. "Durabilidade de fachadas: método de ensaio para verificação da resistência à ação de calor e choque térmico", Revista Ambiente Construído, v.14, n.4, p.53-67, out./dez. 2014.

[17] VARISCO, M. Análise do desempenho de blocos de concreto celular autoclavado em um sistema de vedação externa, Dissertação de M. Sc., Instituto de Engenharia do Paraná, Curitiba, 2014.

[18] ABNT, NBR 10.834: Bloco de solo-cimento sem função estrutural - Requisitos. Rio de Janeiro, ABNT Associação Brasileira de Normas Técnicas, 2013. 
[19] ABNT, NBR 6.459: Solo - Determinação do limite de liquidez, Rio de Janeiro, ABNT - Associação Brasileira de Normas Técnicas, 2016.

[20] ABNT, NBR 7.180: Solo - Determinação do limite de plasticidade, Rio de Janeiro, ABNT - Associação Brasileira de Normas Técnicas, 1988.

[21] ABNT, NBR 7.181: Solo - Análise granulométrica, Rio de Janeiro, ABNT - Associação Brasileira de Normas Técnicas, 2016. 